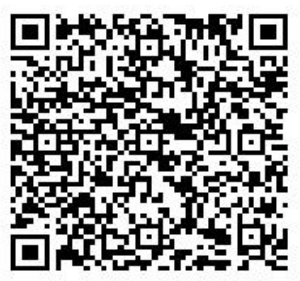

\title{
AN EXPLORATIVE STUDY ON THE PSYCHOSOCIAL DIMENSIONS OF TERRORISM
}

\author{
Raheemudheen $P K^{*}$ and Santhosh $A M^{* *}$
}

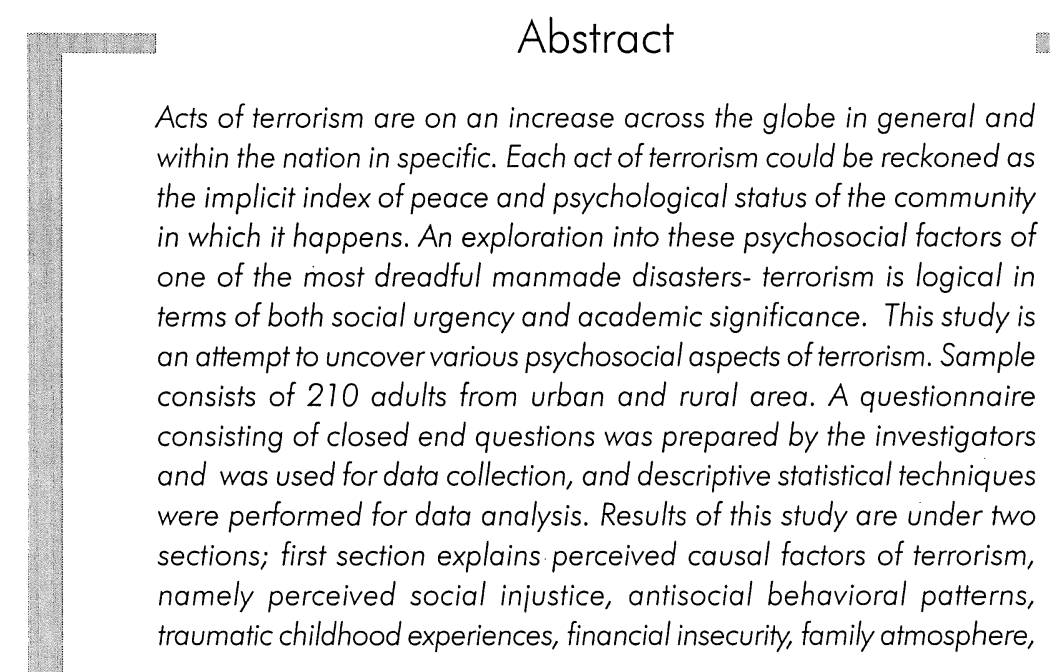

Department of Psychology, University of Delhi, New Delhi.

** Department of Psychology, University of Malaya, Malaysia. 


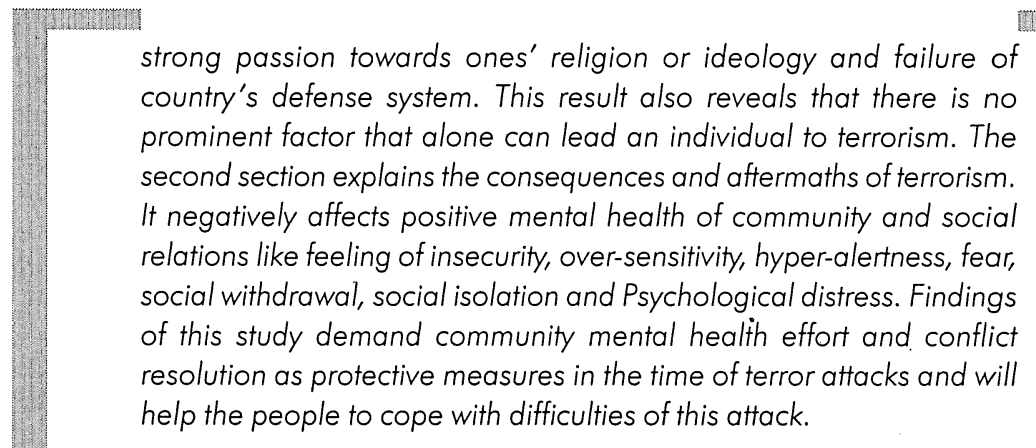

Mncaln

\section{Introduction}

"Mumbai, November 26-29, 2008: in multiple attacks at 10 locations 160 dead, 327 injured, Ahmedabad, September 29, 2008: one bomb blast 1 dead, 15 injured. Delhi, September 13, 2008: five blast in three locations, 26 dead ,43 injured, Ahmedabad, July 26, 2008: Seventeen blast in 10 areas 5 dead, 160injured..., Bangalore, July 25,2008: blast in crowded city 2 dead, 20 injured, Jaipur, May 13,2008: nine blasts in market places 80 dead ,200 injured, Uttar Pradesh, November 23,2007: Six Serial blasts in Varanasi, Faizabad and Lucknow, 14 killed., Hyderabad, August26,2007 twin blasts at Lumbini Garden, 42killed. Hyderabad, May 18, 2007: blast at Mecca Masjith, 12 dead 50 injured. Panipat, February 19, 2007: blast in two coaches of Samihautha Express, 66 Dead." (India Today .Jan, 2009))

It is a chilling Chronicle of the most serious threat that Independent India has had to face. This is a list of the dead and the injured in major terror strikes across India in the past two years. India, along with the rest of the world, is shocked and stunned in the increased attacks by terrorists across the globe, especially in India. There has been a continuous growth of terrorist organizations and activities around the world in the last ten years. Fully militarized and highly trained terrorist organizations have emerged in virtually all countries, with varied political, economic, and other objectives.

In the current national environment, there is little question that terrorism is among the gravest of threats. These terrorist attacks destroy the social, emotional and economic fabric of our community. Since the event of 26th September, Mumbai attacks terrorism has become the subject of intense media interest, political debate and public scrutiny, through well published discussion about motive of terrorism and its consequences in all levels. This situation demands more serious academic 
effort to identify and evaluate the causal factors of terrorism and also its long lasting impact on the bases of Social science research.

The present study is an attempt to uncover various psychosocial aspects of terrorism. Theoretical and empirical based exploration of terrorism is focused on describing and evaluating the perceived causal factors of terrorism according to the public, like injustice from authority, strong influence of ideology from different parts of society, family atmosphere, traumatic childhood experience, poverty, and behavioral trait (Psychopath) and analysis of Psychosocial effects, consequences of terrorism in different dimensions of community, that include impact on community mental health, that means increased terrorist environment will create feeling of insecurity ,fear, uncertainty, over sensitivity, hyper alertness, Post Traumatic Stress Disorder(PTSD)and Social withdrawal etc. All the important integral part of harmonious existences of community.

This empirical based exploration for understanding terrorism, their acts of violence and aftermaths of this dreadful attack is logical in terms of both social urgency and academic significance. Scientific and professional Social Science literatures indicate that terrorism is a relatively recent topic of interest in the field of Psychology. Academic Psychology recognized terrorism as a subject worthy of consideration only in 1982. In that year, Psychological Abstracts listed ten publications under this topic."(Merari 2004). And also there are probably few areas in the social science literature in which so much is written on the basis of so little research, perhaps as much as 80 percent of the literature is not research- based in any rigorous sense. (Schmid \& Jongman, 1988) This void creates a serious challenge at many levels, from policylevel decisions about how a state should respond to terrorism and preventing masers in all level. In individual level decision about disaster preparedness, equipping individuals to attain psychological resistance resources (self-efficacy and social support) have diminished capacity for limiting the negative impact of terrorism and create awareness among people about evil effect of terrorism. So this study will fill that void to an extent.

\section{2: Statement of problem}

This study is titled as "An Exploration into the Psychosocial Dimensions of Terrorism".

\section{3: Objectives of study}

$>$ Broad objective,

To identify and analyze different psychosocial dimensions of terrorism. 
$>$ Specific objectives,

- To explore perceived risk factors of terrorism

- To identify impact of terrorism on community mental health

- To identify impact of terrorism on social relations

- To evaluate the attitude and response of people about contemporary terrorist attacks

\section{4: Hypothesis}

Being an explorative study, hypotheses are not formed.

\section{5: Scope of the study}

A study on intense public \& media interest subject-terrorism, demands more problem oriented studies. Research on this topic has a wide scope, the scope of this study are given below:

- This study will help identify the perceived causal factors of terrorism. It will be useful for strategic planning and policy making of governments and other agencies for controlling and prevention of terrorist activities

- This study will help evaluate the aftermaths of terrorist attacks and possible impact on community mental health and social relations. It will help for strategymaking and module preparation for disaster preparedness.

- This explorative study will be used as a reference for further social science research and academic work on terrorism.

\section{6: Limitations of study}

Some of the identified limitations of the study are given below,

- $\quad$ Purposive sampling method used for sampling, but it is a non probability sampling method.

- Data collected from a small group.

- Most of participants are an indirect victim of terrorism. 
- This study explores only the perceived causal factors according to the participants without any deep analysis and intervention.

\section{Method}

\section{Sampling}

A total of 210 participants were selected by purposive sampling method from adult population (above 18years) in different areas of Kerala. Most of the participants were indirect audience of terrorist attacks but direct victims of terrorist attacks were also included. Samples were distributed according to inclusive criteria of sample like sex of participant (Male \& Female), residential states (urban \& Rural) and educational statues (Higher education- above SSLC \& low educated- below SSLCKerala state).

Table.3.1 Sample distribution based on sex, education, and residence

\begin{tabular}{|l|c|c|c|c|c|}
\hline \multirow{2}{*}{} & \multicolumn{2}{|c|}{ high educated } & \multicolumn{2}{c|}{ low educated } & \multirow{2}{*}{ Total } \\
\cline { 2 - 5 } & Male & Female & Male & Female & \\
\hline Urban & 29 & 25 & 20 & 20 & 94 \\
\hline Rural & 39 & 31 & 26 & 20 & 16 \\
\hline \multirow{2}{*}{ Total } & 68 & 56 & 46 & 40 & \\
\cline { 2 - 5 } & 124 & 86 & 20 & & \\
\hline
\end{tabular}

\section{Measures}

A questionnaire consisting of 26 Closed end questions prepared by the investigator was employed for data collection.

\section{Development of questionnaire;}

This questionnaire is constricted through standardized method. First, around 50 questions were prepared according to different aspects of terrorism. This evaluated and checked its facial validity by a research expert. After that the expert consultation pre-test was conducted on 20 samples. According to responses from pre-test and guideline of the research expert items are modified, expectantly in wording and repetition of items etc. The final questionnaire contains 26 questions in Malayalam language. Questions were arranged with respect to different aspects of terrorism. First part of question (1 to 7) for personal details of respondent, from 8 to 17 
questions for perceived causal factors of terrorism and last part 18 to 26 for impact of terrorism on community mental health and Social relation.

\section{Procedures}

The above mentioned questionnaire was administrated to participants individually. They were provided all the necessary instructions and a short discretion about this study before, had told that their responses would be kept confidentially. After having completed the questionnaire, it was collected back.

\section{Statistical analysis}

The sample analysis was performed by using descriptive statistical techniques.

\section{Result \& Discussion}

Results of this study are arranged with respect to the different aspects of terrorism. In first perceived causal factors were explained, there are total 18 results in this aspect. Second part contains result related to impact of terrorism. It is again divided into different sub groups based on different contributing factors of mental health and social relations. Results are presented by the help of figures and tables. The exact questions which were given to participants are presented before each result. Along with each result a short discussion is also given.

\subsection{1: Do you think terrorism is a major social problem faced by the present society?}

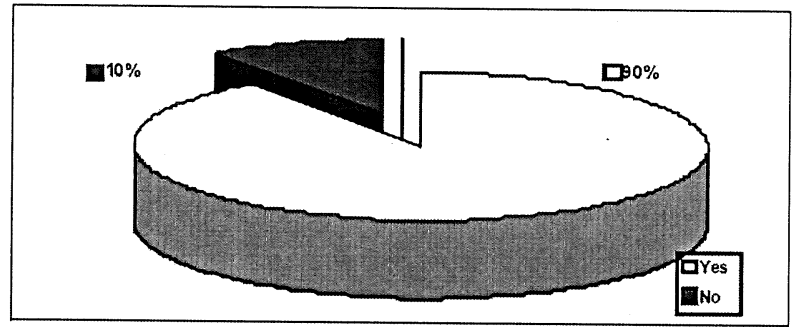

Figure 4.2.1: Terrorism is a response to social injustice 
The above diagram indicates that $90 . \%$ of the respondents considers terrorism as a major social threat, while only $10 \%$ of the respondents feel it is not a threat to the society.

\subsection{2: Perceived causes of terrorism}

\section{4.1.2: Is terrorism a reaction towards social injustices (isolation and separation)?}

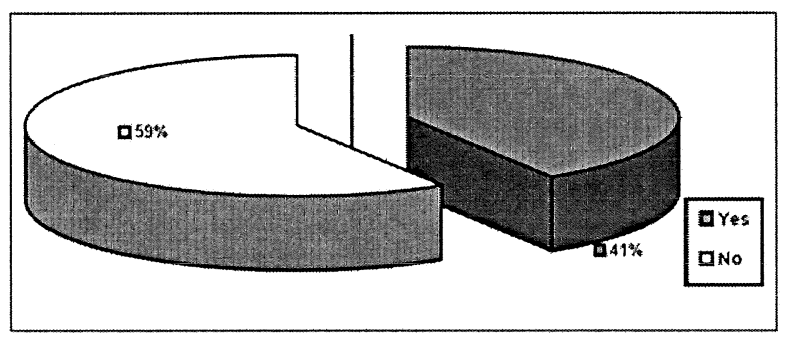

Figure 4.2.2: Terrorism is a response to social injustice

From the above figure it is clear that $41 \%$ of respondents believe that terrorism is the response to social injustice. The study reveals that the negative responsibilities from the part of those in authorities especially administrative and judicial powers enhances the terrorist activities.

\subsection{3: Can the traumatic childhood experiences lead a person into terrorism?}

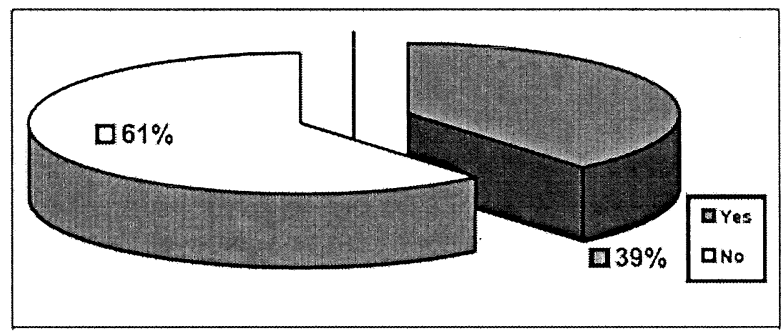

Figure 4.2.3: Role of traumatic childhood experience

The above table indicates that the majority (61.4\%) believes that traumatic childhood experiences don't a make person terrorist. But $38.6 \%$ believe that the early child hood experiences are important determinants for leading a person to terrorism. 
4.2.4: What is the reason youth gets highly attracted to terrorism?

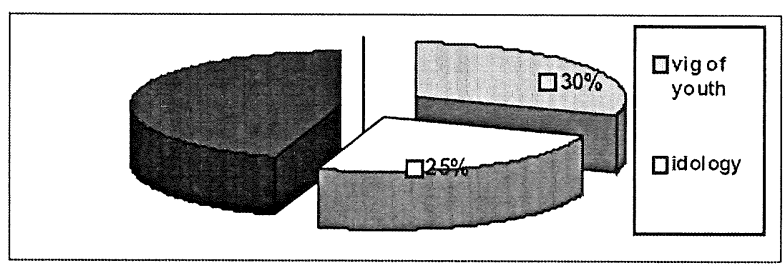

Figure 4.2.4: The reason why youth gets attracted to terrorism?

The above result show that $30 \%$ people believe that vigourness of youth is causal factors of terrorism and $25 \%$ of the participant believe influence of ideology may be causal factors of terrorism while $45 \%$ believe risk factor of terrorism is some thing else.

4.2.5: Do you think that an individual is lead to terrorism due to strong passion towards his nation, class and religion?

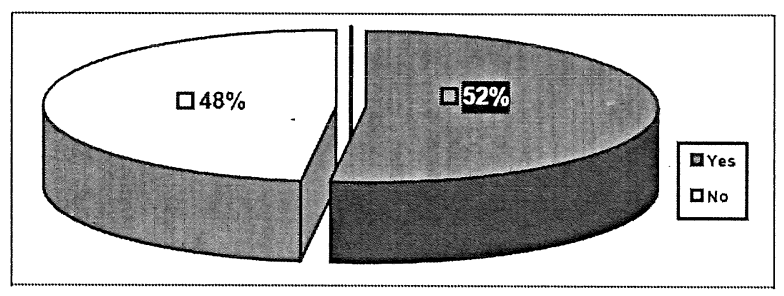

Figure 4.2.5: Causal factor -strong passion towards his nation, class and religion

This result is revealed that $52 \%$ believe that strong passion towards one's nation, class and religion doesn't lead a person to terrorism, While 48 Agrees that the above mentioned view leads a person to terrorism . 
4.2.6 Is financial insecurity or poverty a cause for terrorism?

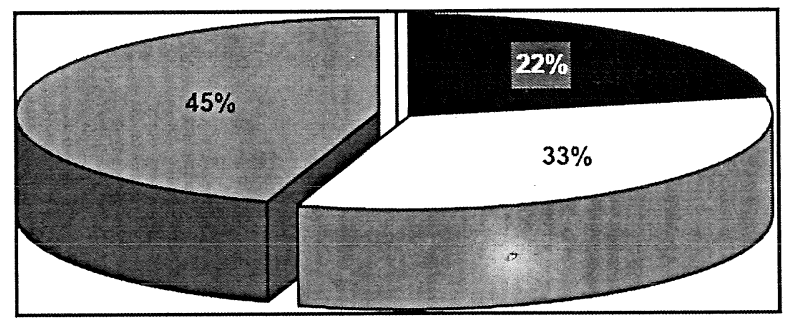

Figure 4.2.6: Financial insecurity as a cause of terrorism

While taking into consideration the role of financial insecurity, only $22 \%$ of the respondents perceive it as a causal factor on the other hand $33 \%$ disagree to this view. But a larger percentage of respondents consider it a causal factor only in some cases.

\subsubsection{Do any religious thoughts or ideology support the terrorism?}

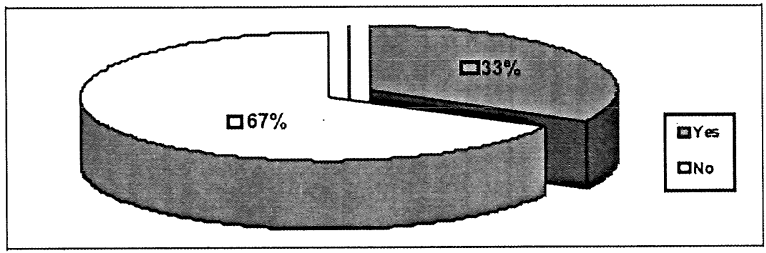

Figure 4.2.7 Religious thoughts or ideology support the terrorism

From the opinion of respondents, it is under study that majority of them perceive that no religious thoughts or ideology support the terrorism. But rest of the respondent perceive it as a cause. 


\subsubsection{Does family atmosphere lead a person to terrorism?}

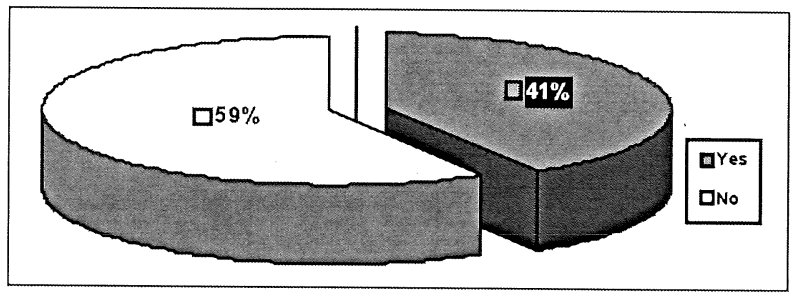

Figure 4.2.8 Family atmosphere leads a person to terrorism

Taking into account the role of family atmosphere or environment, 59\% of the respondents disagree with this statement and $41 \%$ agree that influence of family on individual is an important determinant among factors leading to terrorism. (Figure 4.2.8)

4.2.9 Does any behavioural problem (e.g.: anti-social behaviour) lead an individual to terrorism?

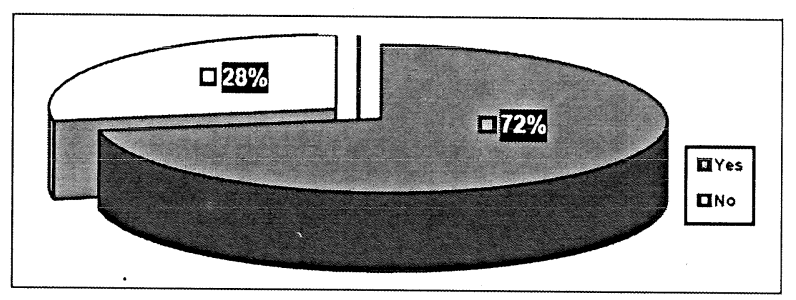

Figure 4.2.9: Casual factor- behavioral problem

From the diagram its clear that majority of respondents (72\%) believe that antisocial personality trait of an individual has key role in making a person terrorist. While small percentage $(28 \%)$ feels that antisocial behavioral patters doesn't necessarily lead a person to be a terrorist. 
4.2.10: Does the failure of defense system of the nation increase terrorist activities?

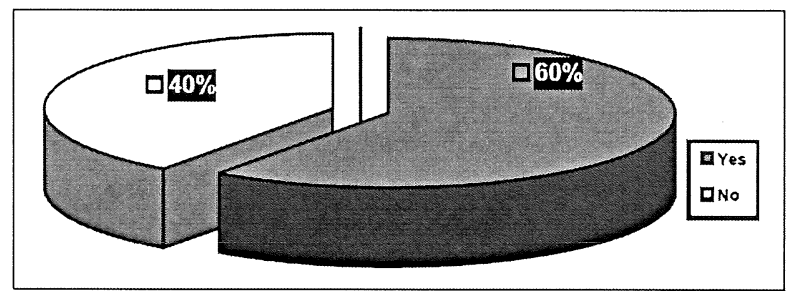

Figure 4.2.10:Casual factor -failure of defense system of nation

Trying to find the role of security system of nation in controlling terrorism, $60 \%$ of the respondents think that there is inefficiency and irresponsibility of nation security. And defense system is perceived as major contributory factor that paves way for terrorism on the other hand $40 \%$ object to this view.

From the above results evident that there is no single factor alone that leads an individual to terrorism. But as per the opinion of the respondents, antisocial behavioral patterns in an individual are the prominent key risk factor among other risk factors of terrorism.

\section{3.: IMPACTS OF TERRORISM ON COMMUNITY MENTAL HEALTH}

Insecurity \& Fear

4.3.1: Do you think increased terrorist activities and attacks effect the security of our nation?

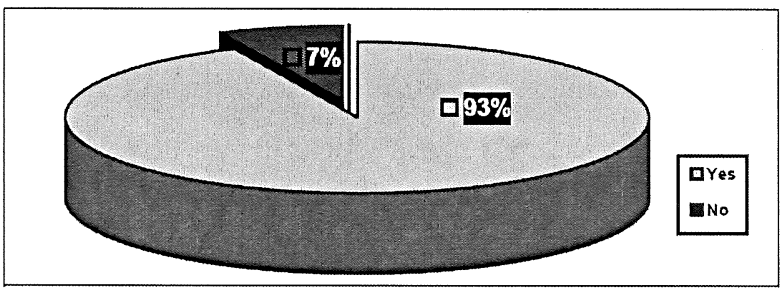

Figure 4.3 .1 ; Impact on security of our nation 
4.3.2: Does a frequent terrorist attack create insecure feeling among people?

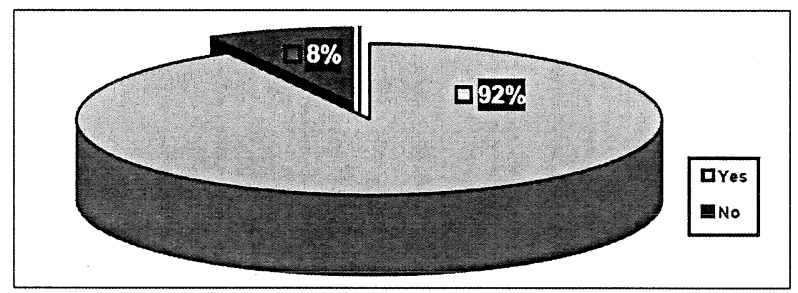

Figure 4.3.2: Impact-insecurity \& Fear-EMBED MSGraph.

Result. 4.3.1 (Figure 4.3.1) indicates that 93.3\% of respondents feel that the terrorist activities and attacks have a negative influence on the security of nation.. From result.4.3.2, (Figure 4.3.2) it is clear that frequent terrorist attacks have created a challenging situation in terms of personal security thus creating a feeling of "insecurity" and "fear". $92.4 \%$ of respondents have agreed to this point

Hyper-alertness

4.3.3: Do small sounds in crowded or public places create fear among people?

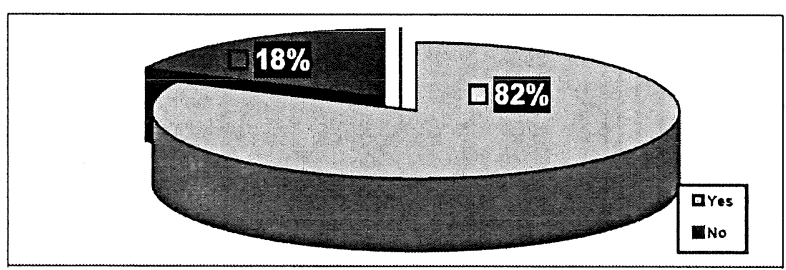

Figure 4.3.3: Impact - Hyper alertness 
4.3.4: Do you feel suspicious while seeing a bag or packets lying unattended?

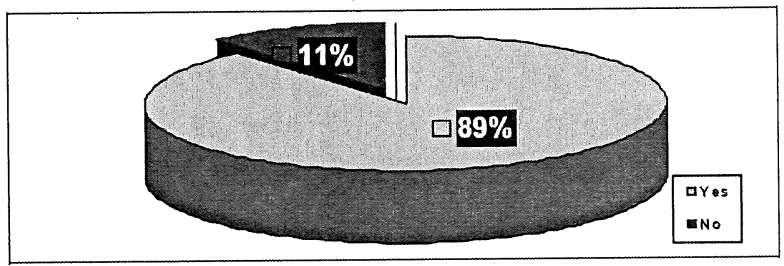

Figure 4.3.4-: Impact- Hyper alertness

It is another impact of terrorism which is of a greater importance From result.4.3.3 (Figure 4.3.3) and Result . 4.3.4(Figure 4.3.4) it is clear that majority of respondents feel that they have become more alert and sensitive to even smaller sounds in open places as they perceive them as indications of some attacks or blasts.

4.3.5: The increased in terrorist activities lead to violent behavior among adolescents and youth

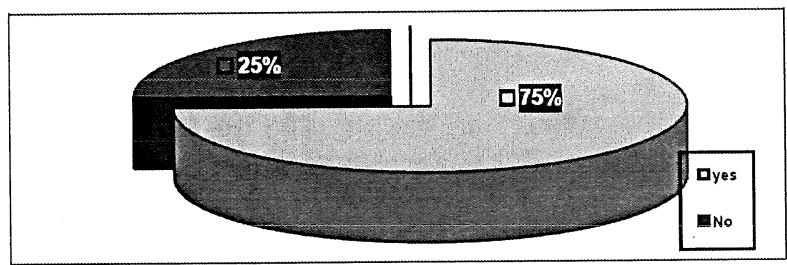

Figure 4.3.5 Impact - modeling in children

4.3.6: Do the terrorist activities carried out in the name of certain ideologies create faulty modeling in children?

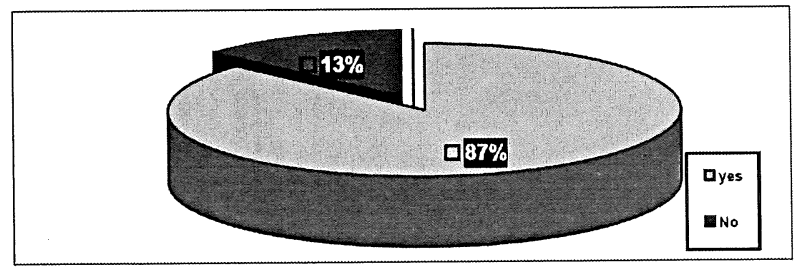

Figure 4.3.6 :Impact - faulty modeling in children 
Results. 4.3.5and result.4.3.6 shows that terrorist activities have a negative impact on youthas well as in children. In children, terrorist activities cause faulty modeling and in youth it causes to enhance aggressive behavior.

\subsection{7: Do you feel fear to interact with strangers during traveling or in public programmes?}

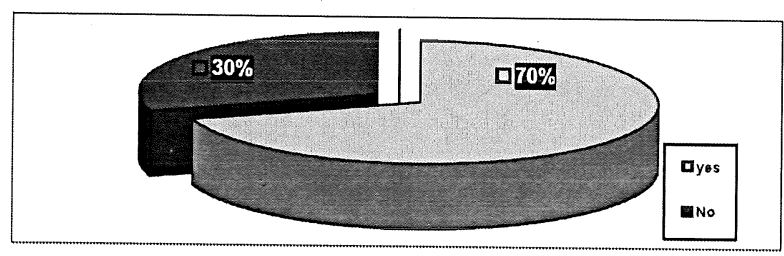

Figure 4.3.7: Impact - Social withdrawal

\subsection{8: Are you afraid to spend more time in crowded cities or public places?}

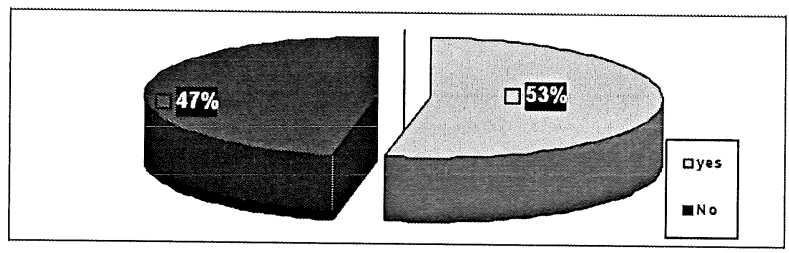

Figure 4.3.8: Impact - Social withdrawal

The above result 4.3 .7 says that $70 \%$ of the respondents feel fear and anxiousness to interact with strangers and result 4.3 .8 reveals that $53 \%$ of respondents are afraid to spend more time in crowded cites. They observe strangers very doubtfully and each and every moment they expect a terrorist attack. It will negatively affect individual social relations and it will lead to Social isolation. 


\section{Personal freedom:-}

\subsection{9: Does the tight security in the name of terrorist attacks make peoples life difficult?}

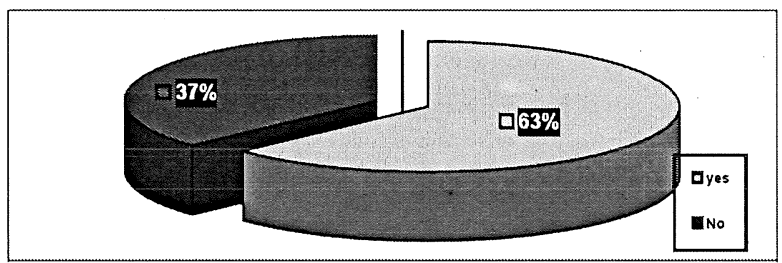

Figure 4.3.9 Impact - Personal freedom

Out of 210 participants of this study $63 \%$ agree that tight security in the name of terrorist attacks makes peoples life difficult. Some of this restriction will be a negative consequent on personal freedom, it's an especially more serious issue in town areas.

From results of above aspects, it is evident that these consequences have a negative impact on the mental health in individual as well as community level. Feeling of insecurity, fear, social withdrawal, oversensitivity, hyper alertness, psychological distress etc. These results throw light on the fact that terrorism remains a great challenge to positive mental health of community.

\section{Conclusions of the study}

- The result of this study makes it evident that people become terrorists in different ways in different roles and for different reasons.

- The first major result reveal some causal factors of terrorism according to public, they are perceived social injustice, antisocial behavioral patterns, traumatic childhood experience, financial insecurity, family atmosphere, strong passion towards ones' religion or ideology and failure of defense system. The second major finding of the study says about consequences of terrorism. It negatively affects some contributing factors of positive mental health and social relations like feeling of insecurity, over-sensitivity, hyper-alertness, fear, social withdrawal, social isolation and Psychological distress 
- The above finding highlight that terrorism became a global reality with very underlining cause, manifestation and impact on public health.

- This demands potential importance of community mental health effort as protective measures in the time of terrorists attacks.

- More research on this subject is necessary to determine its extent to which support helps people to cope with difficulties of this horrible attack

- This study will contribute something to the on-going effort to learn more about psychology of terrorism to some extent.

\section{Suggestions for further studies}

- The present study considers certain perceived causal factors and consequences of terrorism.

- Further studies are possible on cognitive, behavioral \& emotional aspects of terrorism.

- Certain consequences like Post traumatic stress disorder (PTSD), anxiety, aggression, attention deficiency demand more deep clinical oriented research and interventions.

- The results of this study can be utilized for further researches and interventions in related areas like disaster preparedness, rehabilitation, public policy making on terrorism etc.

- The present study was conducted on a smaller sample. A study with a greater sample size and direct victims of terrorist attacks can help to yield better results.

- In this data was collected by using a questionnaire prepared by an investigator himself. Using standardized tools for data collection will help yield more accurate results.

\section{Reference}

- American Psychology Association. (2006). Encyclopedia of psychology. Washington. DC: APA Press.

- Bensaul.(2005).Definition of "Terrorism" in the UN Security Council: 1985-2004. Journal of International Criminal Justice 4 (2006) Vol. 4, No. 1, 141-166 doi:10.1093/chinesejil/ imi005 
- Betty, P., Fefferbaum, M.D. \& Rose, L. (2006). Comparing Stress Responses to Terrorism in Residents of Two Communities Over Time. Brief Treatment and Crisis Intervention / 6:2 May 141.

- Borum, R. (2004). Psychology of terrorism. Tampa: University of South Florida.

- Carson, Bucher and Mineka.(2002) Abnormal Psychology and modern life (7th edt) New Delhi:Pearson Education.

- Crenshaw, M.(1985). The psychology of political terrorism, Political psychology: contemporary problems and issues. London: Josey-Bass.

- Crenshaw, M.(1986). The psychology of political terrorism. London: Josey-Bass.

- Eysenck \& Michael, W. (2003). Key Topics In A2 Psychology. New York: Psychology Press.

- George, P \& Fletcher.(2008). The Indefinable Concept of Terrorism. Journal of International Criminal Justice 4 (2006), 894^91 1 doi:10.1093/iicj/mql060-Oxford University Press, 2006

- Hacker, F.J.(1976). Crusaders, criminals, crazies: terror and terrorism in our time. London: John Wiley.

- Kalayiian, A.(2003).Impact of 9/11terrorism on mental health practitioners in New York. Brief Treatment and Crisis Intervention doi: 10.1146/.54.101601.145112.

- Kashif-ul-Huda.(2000). Psychological impact of violence on Kashmir in India. Retrieve from www. two Circles.net

- Mayors, David, G .(2002).Social Psychology. (7th Edt,).New York: Mc Graw Hill Lit.

- Pandey, S. S. (2006) international terrorism and the contemporary world. New Delhi: Sarup and Sons.

- Sophia, F. \& Dziegielewski.(2002).An Examination of the American Response to Terrorism:Handling the Aftermath Through Crisis Intervention. Brief Treatment and Crisis Intervention 2:287-300. doi: 10.1 146/.54.101601.145112. 